\title{
AVALIAÇÃO DA CAPACIDADE DE REMOÇÃO DE CORANTES ORGÂNICOS EM MEIO AQUOSO POR CARVÕES ATIVADOS OBTIDOS A PARTIR DO ENDOCARPO DA AMÊNDOA-DA-PRAIA (TERMINALIA CATAPPA LINN)
}

\author{
M. F. ALVES ${ }^{1}$, M.V.BORGES ${ }^{2}$, M. J. P. BRITO ${ }^{3}$, K. A. MONTEIRO ${ }^{4 *}$, F. W. A. de JESUS ${ }^{5}$, G. S. \\ NUNES ${ }^{6}$ \\ ${ }^{1,2,3}$ Universidade Estadual do Sudoeste da Bahia, Mestrando do curso de Engenharia e Ciência \\ de Alimentos \\ ${ }^{4}$ Universidade Estadual do Sudoeste da Bahia, Graduando em Engenharia de Alimentos \\ ${ }^{5}$ Universidade Estadual do Sudoeste da Bahia, Departamento de Ciências Exatas e Naturais \\ ${ }^{6}$ Universidade Estadual do Sudoeste da Bahia, Departamento de Estudos Básicos e Instrumentais \\ *email: keivison_almeida@hotmail.com
}

\section{RESUMO}

Neste trabalho objetivou-se avaliar a capacidade de remoção de corantes orgânicos em meio aquoso por carvões ativados (CA) obtidos a partir do endocarpo da amêndoa-dapraia (Terminalia Catappa Linn). O carvão foi preparado pelo método de ativação química usando o carbonato de sódio $\left(\mathrm{Na}_{2} \mathrm{CO}_{3}\right)$, em razões de impregnação (Ri) de 1:1 e 1:2 (massa de ativante/massa da amostra). A carbonização foi conduzida a $600^{\circ} \mathrm{C}$, em mufla por $2 \mathrm{~h}$. Os materiais obtidos foram caracterizados quanto ao teor de umidade, cinzas e $\mathrm{pH}$. Além disso, foram determinados os grupos ácido/base da superfície do CA. O carvão obtido apresentou teor de umidade de 7,43\%, cinzas de 13,75\%, pH de 10,03, $0,68 \mathrm{mmol} . \mathrm{g}^{-1}$ grupos básicos e $0,75 \mathrm{mmol} . \mathrm{g}^{-1}$ grupos ácidos para a razão 1:1 (CA11) e $6,84 \%, 12,03 \%, 10,06,0,53 \mathrm{mmol} . \mathrm{g}^{-1}$ e $0,70 \mathrm{mmol} . \mathrm{g}^{-1}$ respectivamente para a razão $1: 2$ (CA12). No estudo da influência da massa de carvão sobre adsorção do azul de metileno a $50 \mathrm{mg} \mathrm{L}{ }^{-1}$, verificou-se que a massa de $0,03 \mathrm{~g}$ foi a que apresentou capacidade máxima de adsorção do corante, sendo esta massa a escolhida para a realização dos experimentos cinéticos. No experimento de cinética de adsorção, o tempo necessário para que o sistema atingisse o equilíbrio foi de aproximadamente $150 \mathrm{~min}$ para ambas as amostras. A amostra CA11 apresentou porcentagem de remoção máxima de 99,04\%, indicando o melhor desempenho para a adsorção de corantes orgânicos em meio aquoso quando comparada com a amostra CA12.

\section{INTRODUÇÃO}

A poluição de águas é um problema muito persistente e preocupante. $\mathrm{O}$ crescimento intenso e descontrolado de diferentes substâncias tóxicas nos corpos d'água constitui um real perigo para a humanidade. Nas últimas décadas, a legislação ambiental tem se tornado cada vez mais restritiva, devido à conscientização crescente com relação aos riscos para a saúde humana e aos ecossistemas, associados à degradação do ambiente. Assim, muitos esforços têm sido direcionados para o desenvolvimento de 
soluções tecnológicas, para minimizar os impactos ambientais.

Os corantes estão entre os poluentes mais nocivos, os quais são comumente encontrados em águas residuais, geradas por indústrias têxteis, de tintas, alimentícias, plásticas, de cosméticos, gráfica, fotográfica, como aditivos em derivados de petróleo, etc. (GUARANTINI \& ZANONI, 2000; KUNZ et al., 2002).

A presença de corantes nos efluentes é altamente visível, afeta a estética, a transparência da água e a solubilidade de gases nos corpos receptores, reduzindo também a capacidade de regeneração dos corpos hídricos em função da redução da penetração de luz solar e consequente alteração dos processos de fotossíntese (GUARANTINI \& ZANONI, 2000).

A grande diversidade e complexidade desses efluentes aliados às imposições das legislações, as quais exigem tratamentos eficientes, têm levado ao desenvolvimento de novas tecnologias que buscam o melhor e mais adequado tratamento para destruir ou imobilizar compostos orgânicos tóxicos, considerando custos, tempo e eficiência dos processos existentes na eliminação, destoxificação e reaproveitamento de águas industriais. A adsorção apresenta-se como um método alternativo no tratamento de efluentes contendo corantes, pois faz o uso de materiais adsorventes de alta capacidade absortiva como o carvão ativado (LEDAKOWICS, SOLECKA e ZYLLA, 2001).

Entre vários tipos de tratamento, a adsorção é uma das técnicas que tem sido empregada com sucesso na efetiva remoção de corantes (GONÇALVES et al., 2007). Este processo encontra grande aplicação industrial, pois associa custos operacionais relativamente baixos e elevadas taxas de remoção. Além disso, em alguns casos possibilita a recuperação do corante sem perda de sua identidade química por ser um método não destrutivo. O carvão ativado (CA) é o mais popular e eficiente adsorvente usado. Entretanto, o alto custo restringe o seu uso, principalmente em países em desenvolvimento. Uma alternativa viável ao carvão ativado é a utilização de resíduos sólidos que podem ser reciclados e usados como adsorventes de baixo custo e, para este fim, diversos resíduos orgânicos e industriais têm sido testados (KOCH et al., 2002; PERALTA-ZAMORA et al., 1999).

A preparação de carvões ativados a partir de resíduos de biomassa é uma rota economicamente viável e atrativa quanto às promissoras propriedades dos materiais assim produzidos. Muitos trabalhos têm apresentado a investigação destes materiais como adsorventes de resíduos tóxicos (WANG, 2008; SUZUKI et al., 2007; OZDEMIR et al., 2004).

A amendoeira-da-praia (Terminalia Catappa Linn) destaca-se como árvore ornamental que proporciona vasta sombra ao longo das praias da costa brasileira (LIN, 1992; PAULA, 2008) e em muitas cidades da região sudoeste da Bahia. Esta espécie tem sido amplamente estudada quanto ao potencial nutricional da polpa e da castanha e à possibilidade de aplicação dos extratos das folhas e dos frutos como fontes de antioxidantes, corantes naturais e de espécies inibidoras do crescimento de bactérias (PAULA, 2008). No entanto, não há referência de sua utilização como matéria-prima para produção de CA. O endocarpo da amêndoa-dapraia (Terminalia Catappa Linn) pode caracterizar-se como mais uma alternativa de matéria-prima de grande potencial para a produção de CA.

Várias pesquisas têm sido realizadas sobre as propriedades biológicas dessa espécie na saúde humana, tendo sido descritas várias atividades como anti-inflamatória, antitumoral, antiviral e antidiabética. Porém estudos sobre a utilização deste fruto na produção de carvão 
ativado ainda é escasso, com isso pesquisas estão sendo desenvolvidas a fim de verificar se a proposta de utilizar carvão ativado a partir da amêndoa da praia (Terminalia Catappa Linn) como material adsorvente para corantes seja relevante, diante da preocupação ambiental.

Neste contexto, este trabalho tem como objetivos: (i) a preparação de carvão ativado a partir do endocarpo da amêndoa-da-praia (Terminalia Catappa Linn), ativado com $\mathrm{Na}_{2} \mathrm{CO}_{3}$ em razão de impregnação $\left(\mathrm{R}_{\mathrm{i}}\right)$ de $1,0 \mathrm{e}$ 2,0 $\left(\mathrm{R}_{\mathrm{i}}=\right.$ massa do ativante na solução/massa do endocarpo da amêndoa) e submetido a tratamento térmico a $600{ }^{\circ} \mathrm{C}$ por $120 \mathrm{~min}$; (ii) caracterização química dos carvões obtidos; (iii) estudo do efeito de massa de carvão e dos parâmetros cinéticos de adsorção de corantes orgânicos, usando o azul de metileno como composto modelo.

\section{MATERIAL E MÉTODOS}

A etapa de preparação e ativação do carvão foi realizada no Centro de Pesquisa em Química (CEPEQ) da Universidade Estadual do Sudoeste da Bahia (UESB), na cidade de Itapetinga-BA. Os frutos da Terminalia Catappa Linn (amêndoas) foram coletados de árvores ornamentais existentes na cidade de Itapetinga-BA. Os mesmos foram despolpados e expostos ao sol para perda de umidade. Em seguida, os caroços foram quebrados com um auxílio de um martelo para retirada da castanha e diminuir o tamanho de partículas para adequar ao tamanho no moinho de facas. Depois de feita a quebra, o material passou pelo moinho de facas para sua pulverização. Uma massa do material pulverizado foi impregnada com o agente ativante carbonato de sódio $\left(\mathrm{Na}_{2} \mathrm{CO}_{3}\right)$ na razão de (Ri) de 1,0 e 2,0 $(\mathrm{Ri}=$ massa do ativante na solução/massa do endocarpo da amêndoa). À mistura foi adicionada uma quantidade de água destilada, para que ocorresse a impregnação, feito isso a mistura foi aquecida em um agitador magnético, até atingir a temperatura de $85^{\circ} \mathrm{C}$, medida com um termômetro, e sob agitação durante $90 \mathrm{~min}$. Em seguida, a amostra foi seca a $110^{\circ} \mathrm{C}$, em uma estufa, por 12 horas, e posteriormente armazenada em dessecador.

$\mathrm{O}$ material impregnado foi colocado em uma mufla, a uma temperatura de $600^{\circ} \mathrm{C}$, numa taxa de aquecimento de $10^{\circ} \mathrm{C} \mathrm{min}^{-1}$, com tempo de residência de 120 minutos. As amostras foram resfriadas até a temperatura ambiente, dentro de um dessecador.

Após o processo de carbonização, lavouse as amostras com solução de ácido clorídrico $\mathrm{HCl} 2,5 \%(\mathrm{~m} / \mathrm{v})$ e, depois com água destilada quente por várias vezes e, finalmente, com água fria, até o $\mathrm{pH}$ da água de lavagem ficar igual ao $\mathrm{pH}$ inicial da água (aproximadamente neutro). Em seguida, as amostras foram secas, em estufas a $110^{\circ} \mathrm{C}$, por $4 \mathrm{~h}$. E, finalmente, pesados para determinar o rendimento através da Equação 1 e armazenados em frascos fechados em dessecador.

$R_{c}(\%)=\left(\frac{m_{c}}{m_{p}}\right) \times 100$

Em que: $\mathrm{R}_{\mathrm{c}}$ é o rendimento do carvão $(\%), \mathrm{m}_{\mathrm{c}}$ é a massa do carvão obtido $(\mathrm{g})$ e $\mathrm{m}_{\mathrm{p}}$ é a massa do material do precursor $(\mathrm{g})$.

$\mathrm{Na}$ caracterização do carvão ativado (CA), a umidade foi determinada através do método direto para determinação do teor de umidade (PARK e ANTONIO, 2006). A percentagem de cinzas foi determinada com base na norma (ASTM D2866-94, 1999). O $\mathrm{pH}$ foi estabelecido pelo método potenciométrico (JANKOWSKA, SWIATKOWSKI e CHOMA, 1991). Para estimar as propriedades ácido/base da superfície do carvão ativado foi utilizado o método de Bohem (1966).

Para a avaliação da capacidade de remoção de corantes, inicialmente foi feita a curva analítica para o corante azul de metileno (AM) em diferentes concentrações $(0,5,1,3$, 
5, 6, 7, $\left.8 \quad \mathrm{mg} . \mathrm{L}^{-1}\right)$. Estes valores de concentrações foram escolhidos de modo a determinar a faixa linear da relação entre a absorbância e a concentração do AM, em obediência à Lei de Beer-Lambert. A concentração residual do AM na solução após o processo de adsorção foi determinada por espectrofotometria (UV/Vis). Em seguida, foi realizado o estudo para determinar a quantidade suficiente de massa de carvão, para remover ao máximo o adsorbato. Os experimentos foram conduzidos com a diluição de um volume de $153 \mu$ de solução estoque de $\mathrm{AM}$ em concentração de $50 \mathrm{mg}$. $\mathrm{L}^{-1}$ em $10,00 \mathrm{~mL}$ de água destilada, adicionados sobre diferentes quantidades de amostra de carvão $(0,005-0,03 \mathrm{~g})$. A porcentagem de AM removido foi calculada pela Equação 2.

\% removido $=\frac{(\mathrm{Co}-\mathrm{Ce}) \times 100}{\mathrm{Co}}$

Em que, $\mathrm{C}_{\mathrm{O}}$ a concentração inicial do A.M. (mg. $\left.\mathrm{L}^{-1}\right)$ e $\mathrm{C}_{\mathrm{E}}$ a concentração de A.M. no equilíbrio $\left(\mathrm{mg} . \mathrm{L}^{-1}\right)$. As amostras permaneceram sob agitação por 24 horas em temperatura controlada de $25 \pm 1^{\circ} \mathrm{C}$.

Os experimentos cinéticos foram realizados sob agitação, com uma massa de carvão em contato com solução AM a $50 \mathrm{mg}$. $\mathrm{L}^{-1}$, por períodos de $15,30,45,60,90,120$, $150,180,210$ e 240 minutos, à temperatura de $25 \pm 1^{\circ} \mathrm{C}$. Ao término de cada intervalo, as misturas foram centrifugadas, e alíquotas foram coletadas para análise do AM em espectrofotômetro UV/VIS. Os experimentos cinéticos indicaram o tempo necessário para alcançar o equilíbrio de adsorção nas condições experimentais empregadas.

\section{RESULTADOS E DISCUSSÃO}

De acordo com a metodologia empregada para a preparação do carvão, observou-se na Tabela 1 que o rendimento dos carvões ativados nas razões de 1:1 (CA11) e $1: 2$ (CA12) foram de $7,1 \%$ e $4,7 \%$ respectivamente, apresentando assim valores baixos mediante ao método utilizado. Após os processos de carbonização e lavagem, houve uma grande perda da massa final, assim como também a não utilização da atmosfera inerte durante o processo de carbonização pode ter influenciado nessa perda de massa.

Foi notado também que a razão de impregnação pode influenciar no rendimento final do processo, pois o CA11 obteve um maior rendimento quando comparado com CA12.

$\mathrm{Na}$ avaliação do teor de cinzas, a percentagem encontrada nas amostras dos carvões ativados (CA11 e CA12) foram de $13,75 \%$ e $12,03 \%$ respectivamente.

O ideal para o carvão vegetal é que não exceda $4 \%$ de cinzas. Geralmente, as cinzas são indesejáveis em carvões ativados, pois podem alterar o $\mathrm{pH}$ das soluções e contaminálas com sais (BARROS, 2006; JUNIOR, 2010). O aumento do teor de cinzas pode estar relacionado ao método de ativação e ao fato de os compostos inorgânicos presentes no material de partida ficarem retidos (oclusos ou ligados ao material carbonáceo) após o processo de pirólise, não sendo lixiviados no processo de lavagem.

Tabela 1. Valores obtidos pelas caracterizações feitas nas amostras de CA11 e CA12.

\begin{tabular}{ccc}
\hline & CA11 & CA12 \\
\hline Rendimento (\%) & 7,10 & 4,70 \\
Umidade (\%) & 7,43 & 6,84 \\
Cinzas (\%) & 13,75 & 12,03 \\
pH & 10,03 & 10,06 \\
Grupos Básicos & 0,68 & 0,53 \\
$\quad\left(\right.$ mmol.g $^{-1}$ ) & & \\
Grupos Ácidos & 0,75 & 0,70 \\
(mmol.g ${ }^{-1}$ ) & & \\
\hline
\end{tabular}

Fonte: Próprio Autor. 
$\mathrm{Na}$ medida de $\mathrm{pH}$ realizado para a suspensão do carvão ativado em água deionizada, verificou-se que as amostras do $\mathrm{CA}$ nas duas razões apresentou caráter alcalino. $\mathrm{O} \mathrm{pH}$ é fator determinante na carga do adsorvente. Sabe-se que quando um sólido é submerso em água desenvolve sobre sua superfície uma carga proveniente da dissociação dos grupos funcionais, ou da adsorção de íons da solução. Esta carga depende do $\mathrm{pH}$ do meio e das características de superfície (CASTILLA, 2004). Logo, à medida que o $\mathrm{pH}$ aumenta, grupos funcionais fracos se dissociam contribuindo para a capacidade de troca iônica do adsorvente (STRELKO e MALIK, 2002).

Os teores de umidade encontrado nas duas amostras (CA11 e CA12) foram adequados. Já que, segundo Barros (2006) um bom carvão não deve exceder a $8 \%$ de umidade. E a fabricação de carvão com teores de umidade elevados pode diminuir substancialmente sua capacidade adsortiva. (ZAGO, 2010).

Através do método de Boehm foi possível observar pela Tabela 1 que os carvões se caracterizaram por conterem maior quantidade de grupos ácidos em sua superfície. $\mathrm{O}$ que teoricamente contradiz o resultado do $\mathrm{pH}$, porém deve-se levar em consideração que o método de Boehm apresenta limitações e não consegue determinar todos os grupos básicos, possivelmente presentes, na superfície do CA. A superfície do carvão possui características químicas ácidas e básicas. As ácidas associamse as funcionalidades do oxigênio, como carboxilas, lactonas e fenóis. De outro lado, as funções como hidroxila, pirano, éter e carbonila são responsáveis pelas propriedades básicas na superfície do carvão (RAMÓN et al., 1999).

Com relação ao estudo do efeito de massa do carvão, observa-se pela Figura 1 que, no equilíbrio a porcentagem removida é praticamente constante, 99,5\%, acima de 0,0300g para a amostra CA11. Além disso, observa - se que aumentando a massa de carvão no processo de adsorção, a porcentagem adsorvida dos compostos também aumenta até que seja constante. Este efeito ocorre, pois depois de uma determinada quantidade de massa de carvão, é obtido o equilíbrio entre as fases líquida e sólida do composto, ou seja, não haverá mais remoção do composto mesmo aumentando a dosagem de carvão (ÖZKAYA, 2005).

Figura 1- Efeito da massa de carvão sobre a adsorção do AM da amostra CA11.

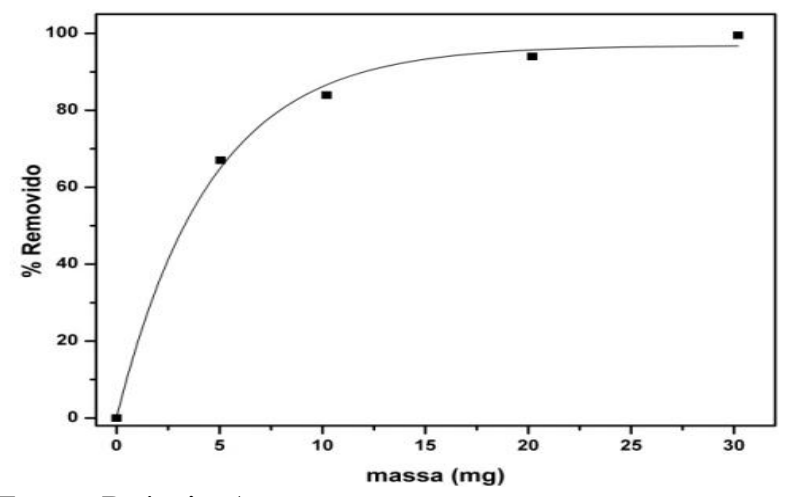

Fonte: Próprio Autor.

Para o estudo do efeito de massa do CA12 como mostra a Figura 2 seria necessária a utilização de valores acima $0,0300 \mathrm{~g}$ para identificar a partir de qual massa o equilíbrio seria atingido.

Figura 2- Efeito da massa de carvão sobre a adsorção do AM da amostra CA12.

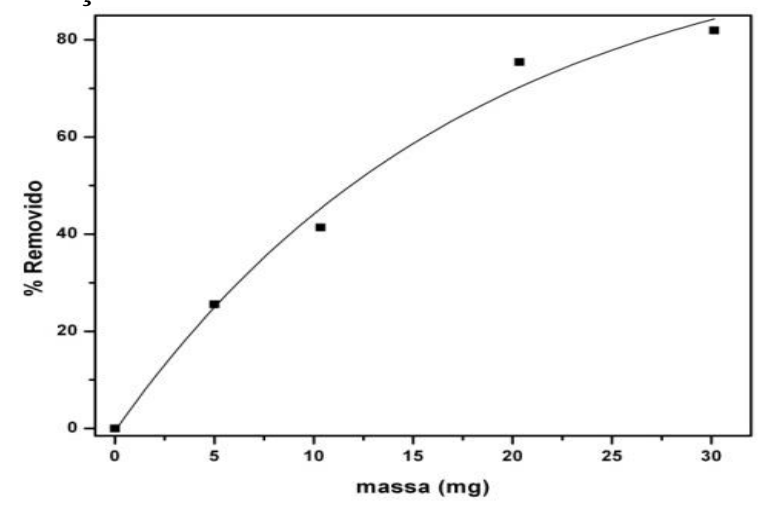

Fonte: Próprio Autor. 
O experimento de cinética de adsorção foi realizado com o objetivo de determinar o tempo necessário para que o sistema atingisse o equilíbrio.

Conforme observado na Figura 3 e 4, o equilíbrio de adsorção para as amostras CA11 e CA12 foi alcançado a partir de $150 \mathrm{~min}$.

Figura 3- Perfil cinético de adsorção do AM sobre a amostra do carvão ativado CA11.

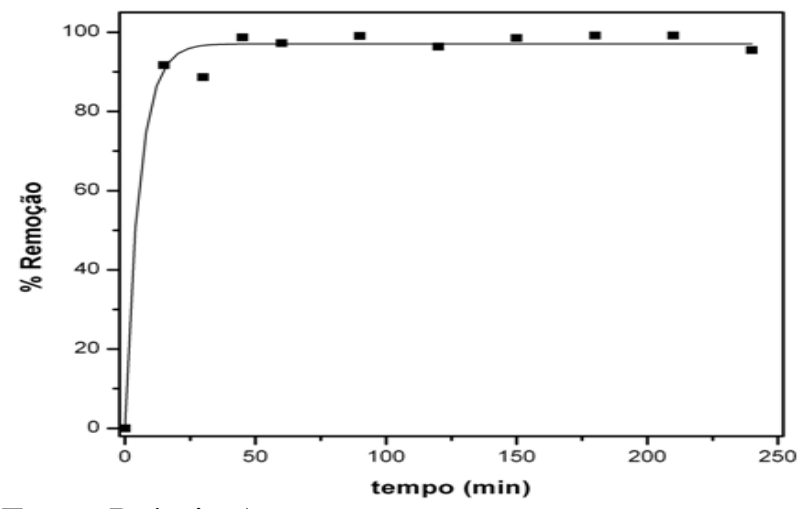

Fonte: Próprio Autor.

Figura 4- Perfil cinético de adsorção do AM sobre a amostra do carvão ativado CA12.

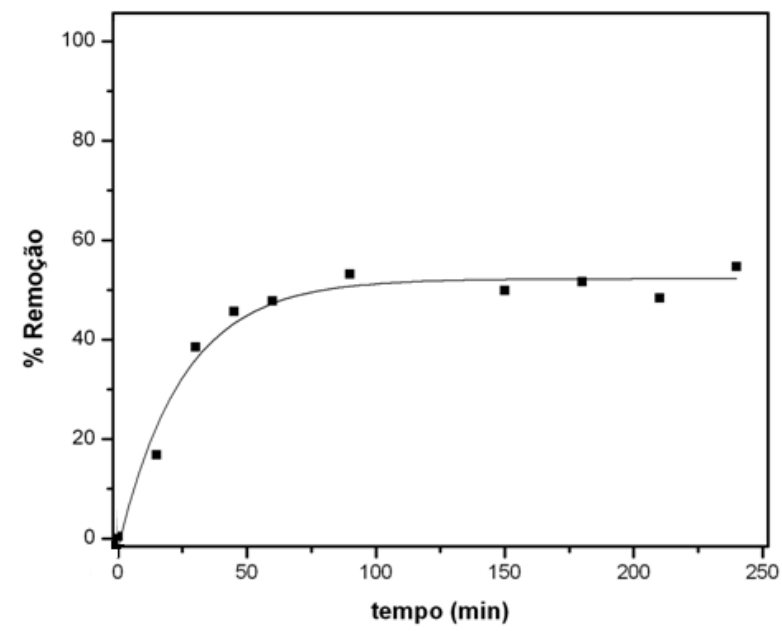

Fonte: Próprio Autor.

A partir deste intervalo de tempo, a variação do percentual adsorvido do corante AM sobre a amostra de CA foi aproximadamente constante, com capacidade máxima de adsorção de aproximadamente 99,04 \% CA11 e 52,6\% para CA12, sugerindo que a amostra CA11, obtida em menor razão de impregnação, apresentou propriedades mais eficientes para a adsorção do corante AM.

\section{CONCLUSÃO}

A produção de carvão ativado a partir da Terminalia Catappa Linn, utilizando-se uma técnica de ativação química com $\mathrm{Na}_{2} \mathrm{CO}_{3}$ apresentou como características alto teor de cinzas, $\mathrm{pH}$ alcalino, umidade dentro dos valores desejáveis e a quantidade de grupos ácidos prevaleceram sobre os grupos básicos nas duas amostras do carvão (CA11 e CA12).

Pelos resultados percentuais obtidos nas cinéticas de adsorção, podemos concluir que para as duas razões de impregnação (CA11 e CA12), o equilíbrio foi atingindo no tempo de 150 min, porém a amostra CA11 apresentou maior percentual de remoção, destacando assim, como o melhor adsorvente para o corante azul de metileno.

Conclui-se também que para amostra CA11 a massa de $0,0300 \mathrm{~g}$ foi suficiente para que adsorção do corante fosse constante. Porém, para o CA12 foi observado que para atingir o equilíbrio, seria necessário uma massa acima de $0,0300 \mathrm{~g}$.

O emprego dessas análises proporciona a possibilidade de oferecer uma contribuição às investigações atuais sobre o mecanismo de ativação dos materiais carbonosos, como também, o possível aproveitamento de uma matéria-prima com boas características para produção de carvão ativado.

\section{NOMENCLATURA}

AM- Azul de metileno

CA- Carvão ativado

CA11- Carvão ativado na razão de impregnação 1:1

CA12- Carvão ativado na razão de impregnação 1:2 
$\mathrm{C}_{\mathrm{E}^{-}}$É a concentração de A.M. no equilíbrio (mg.L $L^{-1}$ )

$\mathrm{C}_{\mathrm{O}-\mathrm{E}}$ a concentração inicial do A.M. (mg. $\mathrm{L}^{-1}$ )

mc-Massa do carvão obtido em gramas

mp- Massa do material do precursor em gramas

Ri- Razão de impregnação

Rc- Rendimento do carvão em porcentagem

UV/VIS- Ultravioleta visível

\section{REFERÊNCIAS}

ASTM D2866-94, Standard test method for total ash content of activated carbon, 1999.

BARROS, S.V.S, 2006. Avaliação da biomassa de espécies exóticas e nativas como fonte alternativa para geração de energia. Dissertação de Mestrado, UFAM, Manaus, AM.

BOEHM, H. P. Advances in Catalysis, v. 16. Academic Press, New York, USA (1966).

CASTILlA, M. C. Eliminación de Contaminantes Orgánicos de lãs águas mediante adsorción em materiales de carbón, Departamento de Química Inorgánica, Facultad de Ciencias, Universidad de Granada, España, 2004.

GONÇALVES, M.; GUERREIRO. M. C.; BIANCHI, M. L.; OLIVEIRA L. C. A.; PEREIRA E. I.; DALLAGO R. M.; Produção de carvão a partir de resíduo de erva-mate para a remoção de contaminantes orgânicos de meio aquoso. Ciênc. Agrotécnicas, Lavras, v. 31, no. 5, p. 1386-1391, Setembro/Outubro, 2007.

GUARANTINI, C. C. I.; ZANONI, M. V. B. Corantes Têxteis. Revista Química Nova, v. 25, n. 1, p. 71-78, 2000.
JANKOWSKA, H.; SWIATKOWSKI, A.; CHOMA, J. Active Carbon. Chichester: Ellis Horwood, 1991.

JUNIOR, O. F. C. Produção de Carvão Ativado a partir de Produtos Residuais de Espécies Nativas da Região Amazônica. Dissertação de Mestrado. Universidade Federal do Paraná. Paraná - PR. 73 p. 2010.

KOCH, M.; YEDILER, A.; LIENERT, D.; INSEL, G.; KETTRUP, A. Ozonation Of Hydrolyzed Azo Dye Reactive Yellow 84. Chemosphere, [S.L.], vol. 46, $\mathrm{n}^{\circ}$. 1, p. 109113, Jan. 2002.

KUNZ, A.; ZAMORA, P. P.; MORAES, S. G.; DURÁN, N. Novas Tendências no Tratamento de Efluentes Têxteis. Revista Química Nova, v. 25, n. 1, p. 78-82, 2002.

LEDAKOWICZ, S.; SOLECKA, M.; ZYLLA, R. Biodegradation, decolourisation and detoxification of textile wastewater enhanced by advanced oxidation process. Journal of Biotechnology, v. 89, p. 175-184, 2001.

LIN, T.-C. Study on the tannins and related compounds in the fruit of Terminalia catappa L. J. Chin. Med. Pharmacol. Res. Vol. 14, p. 165-174, 1992.

OZDEMIR, O.; ARMAGAN, B.; TURAN, M.; CELIK, M. S. Comparison of the adsorption characteristics of azo-reactive dyes on mezoporous mineral. Dyes Pigments, vol. 62, p. 49-60. 2004.

ÖZKAYA, B. Adsorption and desorption of phenol on activated carbon and a comparison of isotherm models. Journal of Hazardous Materials B129 p.158 - 163, Setembro, 2005.

PARK, K.J.; ANTONIO, G.C. Apostila de Análises de materiais biológicos, 2006. 
PAULA, A. A. Caracterização e avaliação do potencial antioxidante in vitro dos frutos da Terminalia Catappa Linn. Dissertação de Mestrado, Universidade Estadual do Sudoeste da Bahia - UESB, Itapetinga - BA. P.77, 2008.

PAUlA, A. A. de.; Caracterização FísicoQuímica e Avaliação do Potencial Antioxidante dos Frutos da Terminalia Catappa Linn. Dissertação de Mestrado, Universidade Estadual do Sudoeste da Bahia UESB, Programa de Pós-Graduação em Engenharia de Alimentos, Itapetinga - BA, 77 p. 2008.

PERALTA-ZAMORA, P.; KUNZ, A.; MORAES, S. G.; PELEGRINI, R.; MOLEIRO, P. C.; REYES, J.; DURÁN, N. Degradation Of Reactive Dyes I: A Comparative Study Of Ozonation, Enzymatic And Photochemical Processes. Chemosphere, [S.L.], vol. 38, no. 4, p. 835-852, February. 1999.

RAMÓN, M. V. L.; STOECKLI, F.; CASTLlA, C. M.; MARÍN, F. C.; On the Chacacterization of Acis and Basic Surface Sites on Carbons by Various Techniques. Carbon 37, p.1215-1221, 1999.

STRELKO, V.; MALIK, D. J. Characterization and metal sorptive properties of oxidized active carbon, J. Colloid Interface Sci., 250:213, 2002.

SUZUKI, R. M.; ANDRADE, A. D.; SOUSA, J. C.; ROLLEMBER, M. C. Preparation and characterization of activated carbon from rice bran. Biorsource Technology, vol. 98 p. 1985-1991, 2007.

WANG, X.; Zhu, N.; Yin, B. Preparation of sludge-based activated carbon and its application in dye wastewater treatment. $\mathbf{J}$. Hazard. Mater. Vol. 153, p. 22-27, 2008.
ZAGO, J.F. Influência das características físico-químicas de carvões ativados na adsorção de saxitoxinas. Tese (Doutorado em Tecnologia Ambiental e Recursos Hídricos). Universidade de Brasília, Brasília-DF, Outubro, 2010.

\section{AGRADECIMENTOS}

Ao Conselho Nacional de Desenvolvimento Científico e Tecnológico (CNPq) pela concessão da bolsa para realização do trabalho. 